\title{
Gross chromosomal rearrangements and genetic exchange between nonhomologous chromosomes following BRCA2 inactivation
}

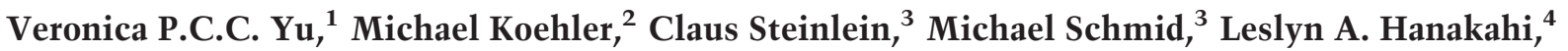 \\ Alain J. van Gool, ${ }^{4,5}$ Stephen C. West, ${ }^{4}$ and Ashok R. Venkitaraman ${ }^{1,6}$ \\ ${ }^{1}$ University of Cambridge, CRC Department of Oncology and The Wellcome Trust Centre for Molecular Mechanisms in \\ Disease, The Cambridge Institute for Medical Research, Cambridge CB2 2XY, UK; ${ }^{2}$ Applied Spectral Imaging GmbH, \\ Technologiezentrum, D-68309 Mannheim, Germany; ${ }^{3}$ Department of Human Genetics, University of Würzburg, \\ Biozentrum, Am Hubland, D-97074 Würzburg, Germany; ${ }^{4}$ ICRF Clare Hall Laboratories, South Mimms, Hertfordshire EN6 \\ $3 \mathrm{LD}, \mathrm{UK}$
}

Cancer-causing mutations often arise from gross chromosomal rearrangements (GCRs) such as translocations, which involve genetic exchange between nonhomologous chromosomes. Here we show that murine Brca2 has an essential function in suppressing GCR formation after chromosome breakage. Cells that harbor truncated Brca2 spontaneously incur GCRs and genomic DNA breaks during division. They exhibit hypersensitivity to DNA damage by interstrand cross-linkers, which even at low doses trigger aberrant genetic exchange between nonhomologous chromosomes. Therefore, genetic instability in Brca2-deficient cells results from the mutagenic processing of spontaneous or induced DNA damage into gross chromosomal rearrangements, providing a mechanistic basis for cancer predisposition.

[Key Words: Breast cancer susceptibility gene; tumor suppressor; translocations; DNA repair; chromosome structure]

Received October 1, 1999; revised version accepted April 12, 2000.

Mutations in the breast cancer susceptibility gene, $B R C A 2$, predispose humans to breast and ovarian cancer. Inheritance of one defective allele confers predisposition, but tumor cells from mutation carriers exhibit loss of heterozygosity (Collins et al. 1995; Gudmundsson et al. 1995). The large, nuclear protein encoded by BRCA2 has been implicated in DNA repair (Connor et al. 1997; Sharan et al. 1997; Patel et al. 1998). It associates with mammalian Rad51 (Sharan et al. 1997; Wong et al. 1997; P.L. Chen et al. 1998), a homolog of RecA essential in bacteria for the repair of DNA breaks by recombination. We have described previously a targeted truncation at residue 1492 in murine Brca2 (designated Brca2 ${ }^{\text {tm1cam }}$, but abbreviated here to Brca2 $2^{\text {Tr }}$ ) designed to model mutations associated with ovarian cancer (Friedman et al. 1998). Consistent with a role in DNA repair, Brca $2^{\operatorname{Tr} / \operatorname{Tr}}$ cells exhibit a heightened sensitivity to genotoxins, although cell cycle checkpoints and the apoptotic response are largely preserved (Patel et al. 1998). The function performed by Brca2 in DNA repair is not known. The cellular abnormalities induced by its truncation sug-

${ }^{5}$ Present address: N.V. Organon, Target Discovery Unit, Oss, The Netherlands.

${ }^{6}$ Corresponding author.

E-MAIL: arv22@cam.ac.uk; FAX 441223336902. gest a defect in homologous recombination (Patel et al. 1998).

A striking feature of Brca2 $2^{\operatorname{Tr} / \operatorname{Tr}}$ cells is that they spontaneously accumulate aberrations in chromosome structure (Patel et al. 1998), also noted in another murine model (Tutt et al. 1999). The abnormalities in Brca2 ${ }^{\operatorname{Tr} / \operatorname{Tr}}$ cells include chromatid and chromosome breaks as well as tri-radial and quadri-radial chromosomes (Patel et al. 1998), reminiscent of the human genetic diseases Bloom's syndrome and Fanconi's anemia, in which chromosomal instability is associated with cancer predisposition. The nature of the aberrations in chromosome structure found in Brca2 $2^{\operatorname{Tr} / \operatorname{Tr}}$ cells is uncertain. Moreover, it remains unclear why they should spontaneously accumulate during cell division in culture.

These issues are of central relevance to cancer predisposition associated with Brca2 truncation (Connor et al. 1997; Friedman et al. 1998). Cancer results from the accrual of mutations that provoke unrestrained cell growth through the activation of proto-oncogenes, or the inactivation of tumor suppressors (Vogelstein and Kinzler 1993). In human cancer cells, these mutations are frequently the result of major chromosomal alterations (for review, see Ponder and Cavanee 1995) such as translocations, inversions, large deletions, and partial or complete loss of chromosomes, generically termed gross chromosomal rearrangements (GCRs). 
Multiple pathways that normally prevent GCRs maintain genome integrity in eukaryotic cells. In Saccharomyces cerevisiae, they involve molecules such as RPA, Rad27, Xrs2, Mre11, and Rad50 that participate in DNA replication or recombination, operating in at least three distinct pathways for GCR suppression (C. Chen et al. 1998; Chen and Kolodner 1999|. Similar pathways are likely to exist in mammalian cells. Mutations that disrupt these poorly understood mechanisms could, by increasing the rate of GCR formation, provoke cancer susceptibility. This prompted us to test the effect of Brca2 truncation on GCRs. Here, we report that Brca2 is an essential component of the pathways that suppress GCR formation in mammalian cells.

\section{Results}

Genomic DNA strand breakage in dividing Brca2 $2^{T r / T r}$ cells

Defective DNA repair in Brca2-deficient cells is accompanied by an impediment to proliferation (Connor et al. 1997; Friedman et al. 1998; Patel et al. 1998). Brca2 ${ }^{\operatorname{Tr} / \operatorname{Tr}}$ cells progressively arrest in the G1 and G2/M phases of the cell cycle during passage in culture, and contain elevated levels of active p53 (Patel et al. 1998). These abnormalities suggest that DNA damage occurs spontaneously in dividing Brca2 $2^{\operatorname{Tr} / \operatorname{Tr}}$ cells. To test this, we examined genomic DNA from asynchronous cultures of dividing $\mathrm{Brca} 2^{\mathrm{Tr} / \mathrm{Tr}}$ lymphocytes for the presence of DNA breakage by pulsed-field gel electrophoresis (PFGE) (Stamato and Denko 1990). Agarose-embedded, high-molecular-weight genomic DNA from control Brca2 $2^{+/}$lymphocytes does not migrate significantly into the gel (Fig. 1A, lane 2, and B). In contrast, genomic DNA from $\mathrm{Brca} 2^{\mathrm{Tr} / \mathrm{Tr}}$ cells migrates (arrows) beyond the origin (Fig. $1 \mathrm{~A}$, lane 4, and B), marking the occurrence of DNA breakage.

This cannot simply be attributed to apoptotic DNA fragmentation in Brca2 $2^{\operatorname{Tr} / T r}$ cells. The DNA fragments detected in $\mathrm{Brca} 2^{\mathrm{Tr} / \mathrm{Tr}}$ cells are large $(>1 \mathrm{Mb})$, whilst even the earliest detectable DNA fragmentation during apoptosis results in fragments no larger than 0.5 Mb (Brown et al. 1993; Oberhammer et al. 1993). Moreover, the percentage of cells spontaneously undergoing apoptosis in Brca $2^{\operatorname{Tr} / \operatorname{Tr}}$ cultures is similar to that in controls as measured by Annexin V staining, an early and sensitive marker (Vermes et al. 1995) for programmed cell death (Fig. 1C).

We substantiated these findings using the highly sensitive TUNEL assay to detect DNA breakage. The free $3^{\prime}$ ends of DNA strand breaks were synthetically labeled with fluorescent d-UTP, and its incorporation measured by flow cytometry. Incorporation was not increased above background levels in control cells (Fig. 1D). In contrast, Brca $2^{\operatorname{Tr} / T r}$ cells stained at a fivefold higher median fluorescence intensity, confirming the occurrence of spontaneous DNA strand breakage despite the absence of increased apoptosis. Collectively, our findings suggest that Brca2 truncation gives rise to DNA double-strand breaks (DSBs) in the genomic DNA of dividing cells.

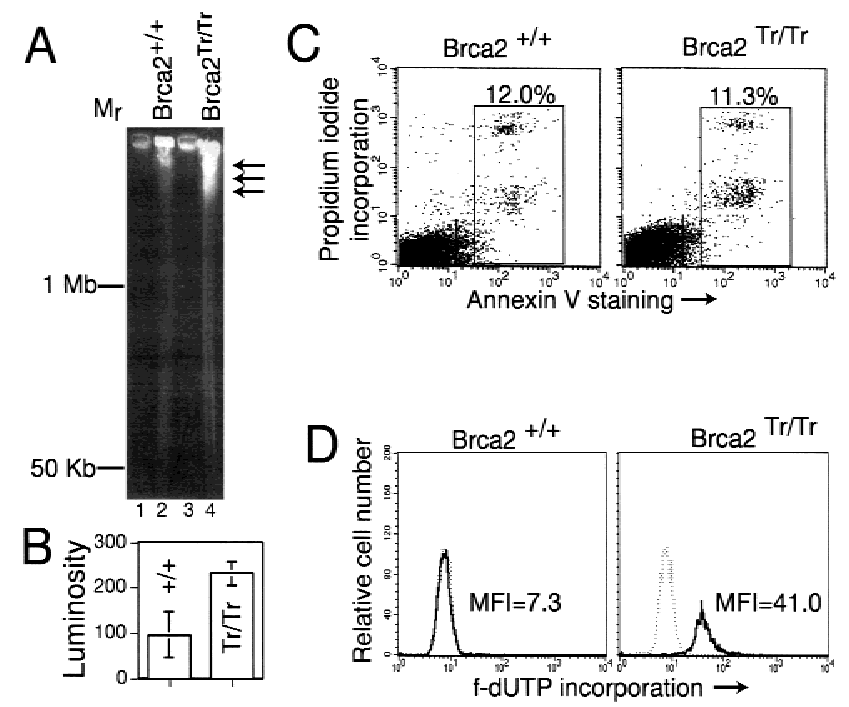

Figure 1. Genomic DNA breakage in dividing Brca2 ${ }^{\operatorname{Tr} / T r}$ cells without increased apoptosis. (A) PFGE analysis of high-molecular-weight DNA from cultures of $\mathrm{Brca}^{+/+}$or $\mathrm{Brca} 2^{\operatorname{Tr} / \mathrm{Tr}}$ cells. Arrows mark the entry of broken DNA into the gel. $(B)$ The mean luminosity of staining ( \pm S.D.) in the gel track excluding the origin is plotted in arbitrary units. $(C)$ Staining with Annexin $\mathrm{V}$, an early marker of apoptosis, is plotted on the x-axis, against propidium iodide incorporation (a late marker), on the $y$. The total percentage of apoptotic cells (boxed) is shown. To avoid bias, forward/side scatter gates were not applied, but as a result some cell debris is included in the box. $(D)$ Incorporation of fluorescent (f-) dUTP into strand breaks is plotted logarithmically on the x-axis, against relative cell number, on the $y$. The dotted histograms in each panel represent the background staining with f-dUTP without TdT addition. The median fluorescence intensity (MFI) of f-dUTP incorporation is indicated.

\section{Random chromosomal rearrangements in Brca2 $2^{T r / T r}$ cells}

DNA breakage in mammalian cells is normally repaired by mechanisms that bias against translocations and other gross chromosomal rearrangements (Richardson et al. 1998). We tested the integrity of these mechanisms in Brca2 ${ }^{\operatorname{Tr} / \operatorname{Tr}}$ cells by detailed examination of chromosome structure using spectral karyotyping (SKY; Liyanage et al. 1996). Metaphases from Brca2 ${ }^{\operatorname{Tr} / T r}$ lymphocytes after 20 passages in culture show a high frequency of chromosomal aberrations (Fig. 2). A representative metaphase (Fig. 2) reveals an acentric fragment containing segments of chromosomes 13,16, and 5, and multiple translocations involving different chromosomes $[\mathrm{t}(\mathrm{X} ; 6), \mathrm{t}(12 ; 16)$, $\mathrm{t}(13 ; 14)$, and $\mathrm{t}(\mathrm{X} ; 16)]$. Such lesions are typically created when interactions between multiple broken DNA ends that bear little or no homology culminate in indiscriminate ligation of one to the other (Phillips and Morgan 1994; Haber and Leung 1996).

All 12 of the Brca2 $2^{\operatorname{Tr} / \operatorname{Tr}}$ metaphases examined contained multiple aberrant chromosomes of this nature, which were not seen in control metaphases. The great majority of the lesions are random-that is, they occur in only a single metaphase (data not shown). The diversity 


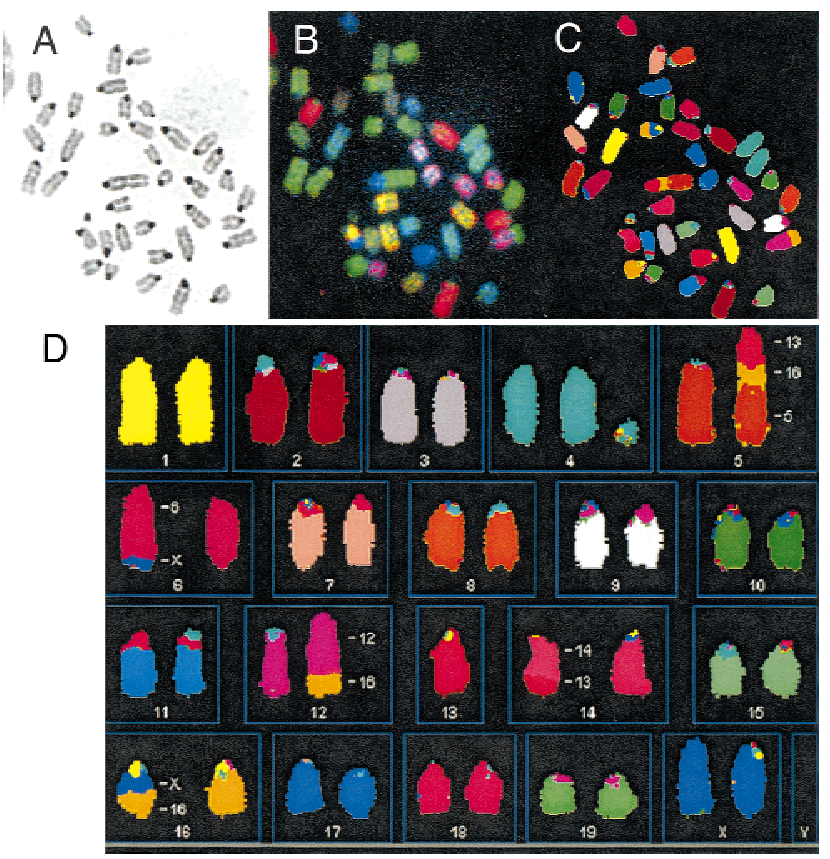

Figure 2. SKY showing analysis of spontaneous chromosome abnormalities in Brca2 ${ }^{\mathrm{Tr} / \mathrm{Tr}}$ cells. (A) Shows a DAPI-banded image of a typical metaphase, after hybridization with fluorescent probes in $B$, and in display colors by assignation of hybridization signals to specific spectral ranges $(C, D)$. $(D)$ Shows multiple abnormalities representing GCRs (see text)

of aberrations in individual metaphases prepared from the same cells at the same time suggests that spontaneous DNA breakage and GCR formation occur continuously during the passage of $\mathrm{Brca} 2^{\operatorname{Tr} / \operatorname{Tr}}$ cells in culture.

\section{Integrity of pathways for DNA break repair}

DNA breaks in mammalian cells are repaired predominantly by two mechanisms (for review, see Hiom 1999). In the first, homologous recombination repair is achieved through interaction of broken DNA with an intact homolog, a process that requires the activity of members of the RAD52 epistasis group, such as Rad51. A second pathway for repair, nonhomologous end joining (NHEJ), works by non-homology-dependent ligation of broken DNA ends, mediated in part through the activity of the DNA-dependent protein kinase (DNA-PK) and its associated proteins $\mathrm{Ku} 70, \mathrm{Ku} 80$, and Xrcc4. We have already reported that $V(D) J$ recombination in developing lymphocytes, an end-joining reaction dependent upon DNA-PK, Ku, and Xrcc4, is unaffected in $\mathrm{Brca}^{\mathrm{Tr} / \mathrm{Tr}} \mathrm{B}$ lymphocytes (Patel et al. 1998).

To confirm this observation and extend its validity to other cell types, we used a recently developed in vitro assay to test if NHEJ was affected by BRCA2 truncation in a human epithelial cell line. CAPAN-1 pancreatic epithelial cells are the only human BRCA2-deficient line currently available. They harbor a truncation of BRCA2 (6174delT) on one allele, whilst the second allele is lost
(Goggins et al. 1996; J. Chen et al. 1998; P.L. Chen et al. 1998). Whole-cell-free extracts from CAPAN-1 cells, and control pancreatic $(\mathrm{PaCa})$ or breast (MCF7) epithelia were examined for their ability to promote the in vitro re-joining of radio-labeled, linear DNA substrates (Baumann and West 1998). As shown in Figure 3, successful NHEJ results in the formation of higher order concatamers (solid arrows) from substrate monomers (open arrow). BRCA2-deficient CAPAN-1 cell extracts are similar in their activity to control extracts in this assay (Fig. 3, cf. lane 2 with lanes 6 and 10). In all cases, NHEJ was dependent on factors known to be involved in Ku-dependent end-joining, as shown by inhibition by wortmannin or anti-Xrcc4 antibodies (lanes 3,4,7,8,11, and 12). A similar experiment is not currently possible using murine $\mathrm{Brca} 2^{\operatorname{Tr} / \mathrm{Tr}}$ cell extracts because a large fraction of NHEJ activity in rodent cell extracts exhibits DNA-PK independence (Baumann and West 1998).

\section{Impaired Rad51 focus formation in Brca $2^{T r / T r}$ cells}

We next examined pathways for repair by homologous recombination. Rad51, a mammalian homolog of bacterial RecA, is central to these pathways through its essential role in the ATP-dependent homologous strand pairing reaction that initiates recombination (Baumann et al. 1996). Rad51 undergoes a characteristic redistribution within the nucleus of cells following DNA damage (Haaf et al. 1995). Distinct subnuclear foci containing Rad51 assemble throughout the nucleus within a few hours after the exposure of cells to $\gamma$-radiation, followed by coalescence into larger structures, thought to constitute sites for the Rad51-dependent repair of DNA damage. The reported co-localization of Brca2 to these Rad51 foci (J. Chen et al. 1998) prompted us to test the integrity of this response.

Accordingly, we examined Rad51 localization in $\mathrm{Brca} 2^{\operatorname{Tr} / \operatorname{Tr}}$ or control cells exposed to $\gamma$-radiation. A few foci containing Rad51 are visible in untreated, dividing $\mathrm{Brca} 2{ }^{\operatorname{Tr} / \operatorname{Tr}}$ cells as well as in $\mathrm{Brca2}^{+/+}$controls (Fig. $4 \mathrm{~A}, \mathrm{C})$, consistent with previous reports (Haaf et al. 1995). Six hours following exposure, the nuclei of control cells are abundantly decorated with sub-nuclear foci con-

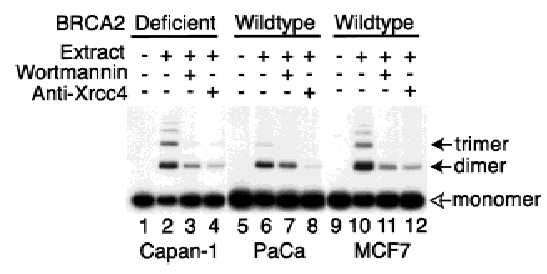

Figure 3. Extracts from BRCA2-deficient CAPAN-1 cells support NHEJ. The radio-labeled monomeric plasmid DNA $13 \mathrm{~kb}$, open arrow) is converted into 6- and 9- kb products (solid arrows) by end-joining in lanes 2,6, and 10. Pre-treatment with wortmannin (lanes $3,7,11$ ) or anti-Xrcc4 (lanes 4,8,12) inhibits end-joining activity. Control extracts were prepared from a pancreatic adenocarcinoma $(\mathrm{PaCa})$ or breast carcinoma (MCF7) cells wild-type for BRCA2. 


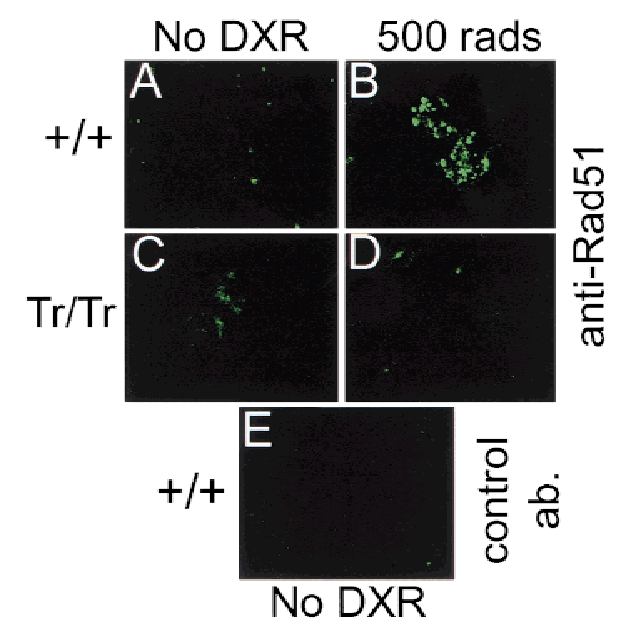

F
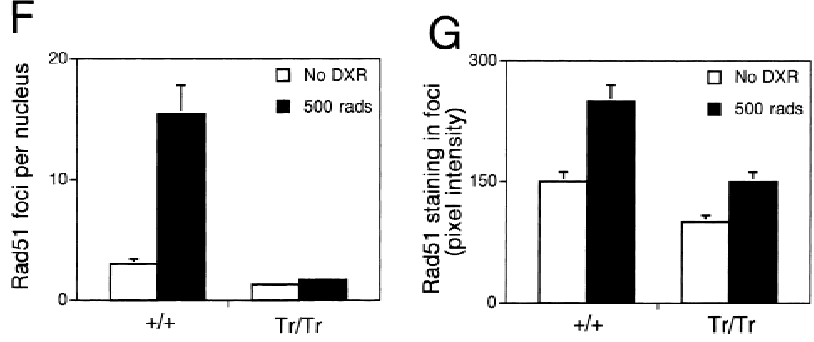

Figure 4. Impaired Rad51 focus formation in Brca2 $2^{\operatorname{Tr} / \mathrm{Tr}}$ cells. $(A-D)$ Show staining for Rad51 before (no DXR) and $6 \mathrm{hr}$ after irradiation. (E) Shows staining with an irrelevant control antiserum.. Background levels of nuclear foci in untreated cells, as well as the foci formed after $\gamma$-radiation, are less numerous $(F)$ and stain less intensely for $\operatorname{Rad} 51(G)$ in $\mathrm{Brca} 2^{\operatorname{Tr} / \operatorname{Tr}}$ cells when compared with controls.

taining Rad51 (Fig. 4B). This response is markedly diminished in Brca2 $2^{\operatorname{Tr} / \mathrm{Tr}}$ cells (Fig. 4D). The average number of foci formed per nucleus is greatly reduced in comparison with wild-type cells (Fig. 4F). Moreover, the size of the foci, as well as the intensity of Rad51 staining within them, is also curtailed (Fig. 4G). Consistent with our findings, failure of focus formation has recently been reported in human BRCA2-deficient cells (Yuan et al. 1999) or cells overexpressing a fragment of BRCA2 with dominant-negative activity (Chen et al. 1999).

\section{Hypersensitivity to DNA cross-linking agents}

Recent evidence suggests that DNA interstrand crosslinks are repaired primarily by recombination between homologous sequences ( $\mathrm{Li}$ et al. 1999). Increased sensitivity to the effects of cross-linking agents such as mitomycin $\mathrm{C}(\mathrm{MMC})$ is a prominent characteristic of mutant cells that lack recombination genes including the Rad51-related proteins, Xrcc2 and Xrcc3 (Liu et al. 1998b). This prompted us to compare the MMC sensitivity of Brca2 $2^{\operatorname{Tr} / T r}$ lymphocytes with that of control cells (Fig. 5A). Measurements were carried out using a colorimetric assay for cell survival, as there is great variability in colony assays performed using the nonadherent, cytokine-dependent pre-B cells. Cell survival is reduced by about twofold when Brca2 ${ }^{\operatorname{Tr} / \operatorname{Tr}}$ cells are treated with MMC at doses that do not cause a similar effect in Brca2 $2^{+/+}$controls.

In recombination-defective $x r c c 2$ and $x r c c 3$ mutant cells, MMC treatment induces chromosome breakage even at low doses that are without a similar effect in controls (Jones et al. 1987; Liu et al. 1998). Existence of a recombination defect in Brca2 $2^{\operatorname{Tr} / \operatorname{Tr}}$ cells would be expected to induce a similar phenotype. In accord with this prediction, whereas chromosome breaks, tri-radial, or quadri-radial chromosomes are not detected in control Brca2 ${ }^{+/+}$cells even after exposure to $1 \mu \mathrm{M} M M C$, their occurrence is increased greatly by 5 - to 10 -fold in Brca $2^{\operatorname{Tr} / \operatorname{Tr}}$ cells at the same dosage (Fig. 5B). Therefore, the decreased survival of Brca2 $2^{\operatorname{Tr} / \operatorname{Tr}}$ cells after MMC treatment is associated with a sharp increase in the incidence of chromosomal aberrations that may reflect ineffectual attempts to repair DNA cross-links by recombination.

\section{Gross chromosomal rearrangements and aberrant genetic exchange after DNA cross-linking}

Spectral karyotyping was used to elucidate more precisely the nature of the chromosomal lesions induced by MMC treatment in Brca $2^{\operatorname{Tr} / \operatorname{Tr}}$ cells. By way of comparison, it is important to emphasize that no abnormalities were detected in metaphases from $\mathrm{Brca}^{+/+}$cells treated with a similar, low dose of MMC (data not shown). In contrast, multiple aberrations are elicited in response to MMC treatment of Brca $2^{\operatorname{Tr} / \operatorname{Tr}}$ cells. Strikingly, many involve genetic exchange between multiple, nonhomologous chromosomes (Fig. 5C-F). The frequency of GCRs detected by SKY analysis (translocations, acentric fragments, and large deletions) is increased following MMC treatment, as is the occurrence of aneuploidy marked by chromosome loss or gain (Fig. 5G). Again, most translocations are confined to a single metaphase (data not shown), demonstrating the random nature of the rearrangements induced by MMC.

\section{Discussion}

Gross chromosomal rearrangements following chromosome breakage in Brca $2^{\text {Tr/Tr}}$ cells

The findings reported here establish that the truncation of Brca2 is sufficient to induce spontaneous GCR formation during the culture of primary cells. The random nature of these chromosome aberrations suggests that the DNA damage that elicits their formation is ongoing. This prediction is validated by the demonstration that DSBs occur in the genomic DNA of dividing, nonapoptotic Brca2 $2^{\operatorname{Tr} / \operatorname{Tr}}$ cells. Truncation of Brca2 also impairs the response to DNA damage induced by the cross-linking agent MMC. Brca2-deficient cells are hypersensitive to the clastogenic effects of MMC, and even at low doses that are without a similar effect in control cells, sustain a variety of GCRs including translocations that involve segments from multiple, nonhomologous chromosomes.

Collectively, these observations indicate that Brca2 has an essential role in the maintenance of genome in- 
Figure 5. Hypersensitivity of $\mathrm{Brca} 2^{\operatorname{Tr} / \operatorname{Tr}}$ cells to mitomycin $\mathrm{C}$ (MMC) triggers aberrant genetic exchange between nonhomologous chromosomes. (A) Cell growth measured by the MTT colorimetric assay is plotted on the $\mathrm{x}$-axis as a percentage relative to the response of untreated cells. The range of variability in the response of individual cultures of Brca2 ${ }^{\operatorname{Tr} / T r}$ lymphocytes is demonstrated by the two curves shown. Results are representative of three independent experiments. (B) MMC exposure induces chromosome aberrations in Brca2 ${ }^{\operatorname{Tr} / T r}$ cells at a dose that is without a similar effect in controls. (n) The number of metaphases examined. $(C-F)$ SKY analysis of a typical individual metaphase as described in Fig. 2. (F) Genetic exchange between multiple nonhomologous chromosomes in the aberrant structures in the lowermost panel. $(G)$ GCRs and aneuploidy marked by chromosome loss or gain is significantly more frequent in $\mathrm{Brca} 2^{\operatorname{Tr} / \operatorname{Tr}}$ cells than in control cells treated with MMC.

tegrity through the suppression of GCRs following spontaneous or induced chromosome damage.

\section{NHEI versus homologous recombination in Brca2 $2^{T r / T r}$ cells}

The role of Brca2 in the suppression of GCRs could conceivably be related to its function in DSB repair. We have already demonstrated that $V(D) J$ recombination, an endjoining reaction dependent on $\mathrm{Ku}, \mathrm{DNA}-\mathrm{PK}$, and Xrcc4, is not impaired in Brca2 $2^{\operatorname{Tr} / \operatorname{Tr}}$ lymphocytes (Patel et al. 1998). We report here, using an in vitro assay, that NHEJ is not affected by a similar BRCA2 truncation in human epithelial cells.

In contrast, several lines of evidence indicate that DNA repair by homologous recombination is defective in $\mathrm{Brca} 2^{\operatorname{Tr} / \operatorname{Tr}}$ cells. We show that the cells are highly sensitive to DNA cross-linking by MMC, a lesion whose repair is dependent on the Rad51-like molecules, Xrcc2 and Xrcc3, essential for recombination (Liu et al. 1998). MMC treatment even at low doses induces a marked increase in the frequency of chromosome breakage in Brca2 ${ }^{\text {Tr/Tr}}$ cells, not observed in wild-type controls. The formation of nuclear foci containing Rad51, presumptive sites for recombination repair following DNA damage, is sharply diminished in Brca $2^{\operatorname{Tr} / \operatorname{Tr}}$ cells. Collectively, our findings provide evidence that the reported physical interaction between Rad51 and Brca2 is of functional significance. Brca1, which interacts with both Brca2 and Rad51, has been shown recently to be essential for homology-mediated DNA repair (Moynahan et al. 1999).

There is evidence that the resolution of chromosome breakage by non-homology-dependent mechanisms is
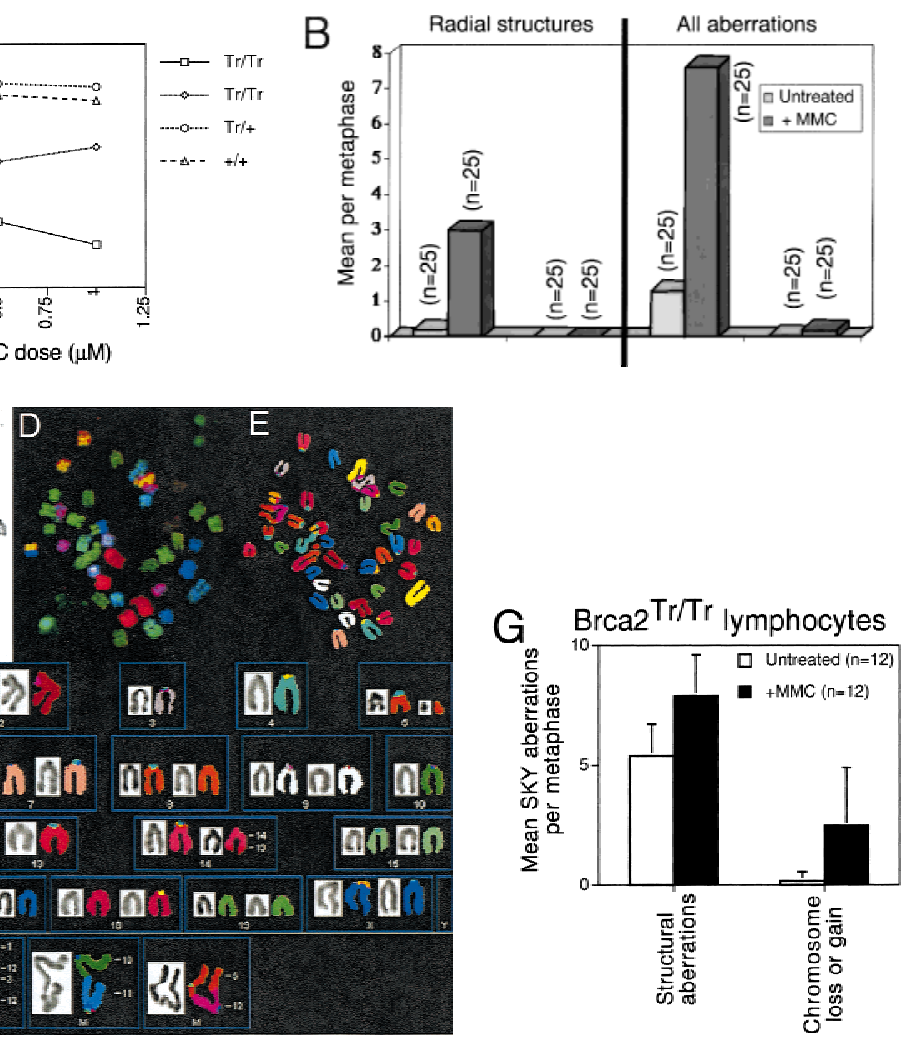

more likely to cause GCRs than homologous recombination. Sequence analysis at the breakpoints of translocations triggered by severe chromosome breakage suggests that they occur through the rejoining of nonhomologous broken ends from heterologous chromosomes (Phillips and Morgan 1994; Haber and Leung 1996). Conversely, disruption of Mre11, Rad50, or Xrs2, required for homologous recombination in yeast, increases the frequency of GCR formation by several orders of magnitude (Chen and Kolodner 1999|; and mammalian homologs of these proteins also associate with BRCA1 (Zhong et al. 1999). When viewed in light of the evidence that Rad51 is essential for homologous recombination (Baumann et al. 1996; Benson et al. 1998), the results presented here are consistent with the notion that the requirement for Brca2 in the prevention of GCRs is related to its role in Rad51-dependent mechanisms for DSB repair, although it cannot be excluded that another defective interaction is involved.

\section{Implications for cancer predisposition associated with BRCA2 mutations}

Large deletion mutations, chromosomal translocations, and partial or complete chromosome loss have been identified repeatedly in human cancer cells as loss of heterozygosity (LOH) at genetic loci implicated in neoplastic transformation (Ponder and Cavanee 1995). LOH may underlie the events that foster transformation, such as the loss of a tumor suppressor gene, or the activation of a cellular proto-oncogene /Vogelstein and Kinzler 1993). Our results indicate that inactivation of BRCA2 greatly enhances the frequency of gross chromosomal rearrangements that may cause $\mathrm{LOH}$ at functionally im- 
BRCA2 suppresses gross chromosomal rearrangements

portant genetic loci. We propose on this basis that it is the loss of an essential function of BRCA2 in the maintenance of chromosomal stability that triggers the additional genetic changes necessary for neoplastic transformation in individuals who carry germ-line mutations. Our model is strongly supported by the observation that chromosomal rearrangements are more frequent in primary breast cancers associated with $B R C A 1$ and $B R C A 2$ mutations (Gretarsdottir et al. 1998).

\section{Materials and methods}

\section{Culture of fetal liver B lymphocytes}

Fetal liver cultures from day 17 embryos were initiated as previously described (Patel et al., 1998). Established cultures were passaged at $20 \%$ confluence.

\section{PFGE}

Wild-type or Brca2 ${ }^{\operatorname{Tr} / \operatorname{Tr}}$ lymphocytes $\left(2 \times 10^{7}\right)$ were embedded in $2 \%$ Clearcut (Biorad) agarose plugs. The solidified plugs were incubated overnight in Proteinase $\mathrm{K}$ buffer (100 mM EDTA at $\mathrm{pH} 8.0,0.2 \%$ sodium deoxycholate, $1 \%$ sodium lauryl sarcosine) with $0.2 \mathrm{mg} / \mathrm{ml}$ of Proteinase $\mathrm{K}$ at $50^{\circ} \mathrm{C}$. After several washes in $20 \mathrm{~mm}$ Tris at $\mathrm{pH} 8.8,50 \mathrm{~mm}$ EDTA, the plugs were loaded into the wells of a $1 \%$ agarose gel. Genomic DNA was separated in a CHEF-DRIII pulsed-field electrophoresis system (BioRad) at $6 \mathrm{~V} / \mathrm{cm}$ in $0.5 \times$ TBE $(45 \mathrm{~mm}$ Tris, $45 \mathrm{~mm}$ borate, 1 mM EDTA at $\mathrm{pH} 8.3$ ) buffer, at an angle of $120^{\circ}$ and a ramped switch time from 60 to $120 \mathrm{sec}$ over $24 \mathrm{hr}$. The gel was then stained for $10-40 \mathrm{~min}$ in $30 \mathrm{\mu g} / \mathrm{ml}$ of ethidium bromide. Quantitation was by densitometry using a Molecular Dynamics device.

\section{Annexin $V$ staining}

Cells $\left(1 \times 10^{6}\right)$ were incubated in $100 \mu \mathrm{l}$ of labeling solution (10 mM HEPES at pH 7.4, $140 \mathrm{~mm} \mathrm{NaCl}, 5 \mathrm{mM} \mathrm{CaCl}_{2}$ ) containing 2 $\mathrm{ll}$ of FITC-labeled Annexin V (Boehringer Mannheim) and 1 $\mu \mathrm{g} / \mathrm{ml}$ of propidium iodide for $15 \mathrm{~min}$ in the dark before analysis by flow cytometry as below.

\section{TUNEL assay}

Cells $\left(1 \times 10^{6}\right)$ were analyzed per sample using the APO-DIRECT reagents (Pharmingen, San Diego, CA) according to manufacturer's instructions. Flow cytometry was performed on a Becton Dickinson FACSCalibur instrument using CellQuest software. Ten thousand events were acquired per sample.

\section{NHEJ assay}

In vitro, nonhomologous end-joining assay was carried out as described previously (Baumann and West 1998), using extracts prepared from $3 \times 10^{9} \mathrm{CAPAN}-1$ or control cells. Inhibitors (anti-human Xrcc4 at 1:250 dilution or $0.3 \mu \mathrm{M}$ wortmannin) were added directly to the end-joining reactions.

\section{Cytogenetics}

Metaphases from mutant or control lymphocytes were prepared as previously described (Patel et al., 1998). Individual metaphases were photographed. Photographs were shuffled and scored blind for the presence of structural chromosomal aberrations /chromatid/chromosome breaks, tri-radials, quadri-radials, complex chromatid exchanges) as described by Savage (1975).

\section{Spectral karyotyping}

Metaphases were hybridized with SkyPaint probes (Applied Spectral Imaging, Mannheim, Germany) according to the manufacturer's instructions (Liyanage et al. 1996), mounted with 20 $\mu \mathrm{l}$ DAPI/anti-fade solution and analyzed using the SkyVision spectral imaging system.

\section{Immunostaining for Rad51 foci after irradiation}

B lymphocytes were either untreated or exposed to 500 rads in an X-ray generator (Torres 150D, EG and G Astrophysics Research, Long Beach, CA). After irradiation, cells were incubated at $37^{\circ} \mathrm{C}$ for $6 \mathrm{hr}$. Immunostaining of Rad51 foci was carried out as described previously (Scully et al. 1997) using antiserum against Rad51 (FBE-1), or pre-immune serum, detected with FITC-conjugated anti-rabbit secondary antibodies (Jackson Immunoresearch, West Grove, PA). Image analysis was carried out on a Bio-Rad 1000 confocal microscope.

\section{MMC sensitivity}

Cells $\left(4 \times 10^{4}\right)$ in $100 \mu$ in round-bottom 96-well plates (Falcon) were treated with mitomycin C (Sigma) at the indicated concentrations for $24 \mathrm{hr}$. The MTT colorimetric assay (Boehringer Mannheim, Germany) was carried out according to the manufacturer's instructions. Each experimental point was calculated from triplicate repeats.

\section{Acknowledgments}

We thank D. Winder and B. Randhawa for assistance with largescale CAPAN-1 and PaCa cultures; Dr. G. Ihrke for assistance with confocal imaging; and Dr. A. Philpott for thoughtful criticism of this manuscript. V.P.C.C.Y. was supported by a $\mathrm{PhD}$ studentship from the James Baird Trust and the National Radiological Protection Board. L.H. is supported by a Fellowship from the Human Frontiers Program and work in S.C.W.'s lab is supported by the Imperial Cancer Research Fund and the Human Frontiers Program. A.R.V. holds a Professorship endowed by the late Dr. F.A. Zoellner. Research in A.R.V.'s lab is supported by the Medical Research Council.

The publication costs of this article were defrayed in part by payment of page charges. This article must therefore be hereby marked "advertisement" in accordance with 18 USC section 1734 solely to indicate this fact.

\section{References}

Baumann, P. and S.C. West. 1998. DNA end-joining catalyzed by human cell-free extracts. Proc. Natl. Acad. Sci. 95: 14066-14070.

Baumann, P., F.E. Benson, and S.C. West. 1996. Human Rad51 protein promotes ATP-dependent homologous pairing and strand transfer reactions in vitro. Cell 87: 757-766.

Benson, F.E., P. Baumann, and S.C. West. 1998. Synergistic actions of Rad51 and Rad52 in recombination and DNA repair. Nature 391: 401-404.

Brown, D.G., X.M. Sun, and G.M. Cohen. 1993. Dexamethasone-induced apoptosis involves cleavage of DNA to large fragments prior to internucleosomal fragmentation. J. Biol. Chem. 268: 3037-3039.

Chen, C. and R.D. Kolodner. 1999. Gross chromosomal rearrangements in S. cerevisiae replication and recombination defective mutants. Nat. Genet. 23: 81-85.

Chen, C., K. Umezu, and R.D. Kolodner. 1998. Chromosomal rearrangements occur in S. cerevisiae rfa1 mutator mutants due to mutagenic lesions processed by double-strand-break repair. Mol. Cell 2: 9-22. 
Chen, J., D.P. Silver, D. Walpita, S.B. Cantor, A.F. Gazdar, G. Tomlinson, F.J. Couch, B.L. Weber, T. Ashley, D.M. Livingston, and R. Scully. 1998. Stable interaction between the products of the BRCA1 and BRCA2 tumor suppressor genes in mitotic and meiotic cells. Mol. Cell 2: 317-328.

Chen, P.L., C.F. Chen, Y. Chen, J. Xiao, Z.D. Sharp, and W.H. Lee. 1998. The BRC repeats in BRCA2 are critical for Rad51 binding and resistance to methyl methanesulfonate treatment. Proc. Natl. Acad. Sci. 95: 5287-5292.

Chen, C.F., P.L. Chen, Q. Zhong, Z.D. Sharp, and W.H. Lee. 1999. Expression of BRC repeats in breast cancer cells disrupts the BRCA2- Rad51 complex and leads to radiation hypersensitivity and loss of G(2)/M checkpoint control. J. Biol. Chem. 274: 32931-32935.

Collins, N., R. McManus, R. Wooster, J. Mangion, S. Seal, S. Lakhani, W. Ormiston, and P.A. Daly. 1995. Consistent loss of the wild-type allele in breast cancers from a family linked to the BRCA2 gene on chromosome 13q12-13. Oncogene 10: $1673-1675$.

Connor, F., D. Bertwistle, P.J. Mee, G.M. Ross, S. Swift, E. Grigorieva, V.L. Tybulewicz, and A. Ashworth. 1997. Tumorigenesis and a DNA repair defect in mice with a truncating Brca2 mutation. Nat. Genet. 17: 423-430.

Friedman, L.S., F.C. Thistlethwaite, K.J. Patel, V.P.C.C. Yu, H. Lee, A.R. Venkitaraman, K.J. Abel, M.B. Carlton, S.M. Hunter, W.H. Colledge et al. 1998. Thymic lymphomas in mice with a truncating mutation in Brca2. Cancer Res. 58: $1338-1343$.

Goggins, M., M. Schutte, J. Lu, C.A. Moskaluk, C.L. Weinstein, G.M. Petersen, C.J. Yeo, C.E. Jackson, H.T. Lynch, R.H. Hruban, and S.E. Kern. 1996. Germline BRCA2 gene mutations in patients with apparently sporadic pancreatic carcinomas. Cancer Res. 56: 5360-5364.

Gretarsdottir, S., S. Thorlacius, R. Valgardsdottir, S. Gudlaugsdottir, S. Sigurdsson, M. Steinarsdottir, J.G. Jonasson, K. Anamthawat-Jonsson, and J.E. Eyfjord. 1998. BRCA2 and p53 mutations in primary breast cancer in relation to genetic instability. Cancer Res. 58: 859-862.

Gudmundsson, J., G. Johannesdottir, J. Bergthorsson, A. Arason, S. Ingvarsson, V. Egilsson, and R. Barkardottir. 1995. Different tumour types from BRCA2 carriers show wild-type chromosome deletions on 13q12q13. Cancer Res. 55: 4830-4832.

Haaf, T., E.I. Golub, G. Reddy, C.M. Radding, and D.C. Ward. 1995. Nuclear foci of mammalian Rad51 recombination protein in somatic cells after DNA damage and its localization in synaptonemal complexes. Proc. Natl. Acad. Sci. 92: 22982302.

Haber, J.E., and W.Y. Leung. 1996. Lack of chromosome territoriality in yeast: Promiscuous rejoining of broken chromosome ends. Proc. Natl. Acad. Sci. 93: 13949-13954.

Hiom, K. 1999. Rad52-the means to an end. Curr. Biol. 9: R446R448.

Jones, N.J., R. Cox, and J. Thacker. 1987. Isolation and crosssensitivity of X-ray-sensitive mutants of V79-4 hamster cells. Mutat. Res. 183: 279-286.

Li, L., C.A. Peterson, X. Lu, P. Wei, and R.J. Legerski. 1999. Interstrand cross-links induce DNA synthesis in damaged and undamaged plasmids in mammalian cell extracts. Mol. Cell. Biol. 19: 5619-5630.

Liang, F., M. Han, P.J. Romanienko, and M. Jasin. 1998. Homology-directed repair is a major double-strand break repair pathway in mammalian cells. Proc. Natl. Acad. Sci. 95: 5172-5177.

Liu, N., J.E. Lamerdin, R.S. Tebbs, D. Schild, J.D. Tucker, M.R. Shen, K.W. Brookman, M.J. Siciliano, C.A. Walter, W. Fan et al. 1998a. XRCC2 and XRCC3, new human Rad51-family members, promote chromosome stability and protect against DNA cross-links and other damages. Mol. Cell 1: 783-793.

Liyanage, M., A. Coleman, S. du Manoir, T. Veldman, S. McCormack, R.B. Dickson, C. Barlow, A. Wynshaw-Boris, S. Janz, J. Wienberg et al. 1996. Multicolour spectral karyotyping of mouse chromosomes. Nat. Genet. 14: 312-315.

Moynahan, M.E., J.W. Chiu, B.H. Koller, and M. Jasin. 1999. Brcal controls homology-directed DNA repair. Mol. Cell 4: 511-518.

Oberhammer, F., J.W. Wilson, C. Dive, I.D. Morris, J.A. Hickman, A.E. Wakeling, P.R. Walker, and M. Sikorska. 1993. Apoptotic death in epithelial cells: Cleavage of DNA to 300 and/or $50 \mathrm{~kb}$ fragments prior to or in the absence of internucleosomal fragmentation. EMBO J. 12: 3679-3684.

Patel, K.J., V.P.C.C. Yu, H. Lee, A. Corcoran, F.C. Thistlethwaite, M.J. Evans, W.H. Colledge, L.S. Friedman, B.A. Ponder, and A.R. Venkitaraman. 1998. Involvement of Brca2 in DNA repair. Mol. Cell 1: 347-357.

Phillips, J.W., and W.F. Morgan. 1994. Illegitimate recombination induced by DNA double-strand breaks in a mammalian chromosome. Mol. Cell. Biol. 14: 5794-5803.

Ponder, B.A.J., and W.K. Cavanee. 1995. Genetics and cancer: A second look. Cold Spring Harbor Laboratory Press, Cold Spring Harbor, N.Y.

Richardson, C., M.E. Moynahan, and M. Jasin. 1998. Doublestrand break repair by interchromosomal recombination: Suppression of chromosomal translocations. Genes \& Dev. 12: $3831-3842$.

Savage, J.R.K. 1975. Classification and relationships of induced chromosomal structural changes. J. Med. Genetics 12: 103 122.

Scully, R., J. Chen, A. Plug, Y. Xiao, D. Weaver, J. Feunteun, T. Ashley, and D.M. Livingston. 1997. Association of BRCA1 with Rad51 in mitotic and meiotic cells. Cell 88: 265-275.

Sharan, S.K., M. Morimatsu, U. Albrecht, D. Lim, E. Regel, C. Dinh, A. Sands, G. Eichele, P. Hasty, and A. Bradley. 1997. Embryonic lethality and radiation hypersensitivity mediated by Rad51 in mice lacking Brca2. Nature 386: 804-810.

Stamato, T.D., and N. Denko. 1990. Asymmetric field inversion gel electrophoresis: A new method for detecting DNA double-strand breaks in mammalian cells. Radiat. Res. 121: 196-205.

Tutt, A., A. Gabriel, D. Bertwistle, F. Connor, H. Paterson, J. Peacock, G. Ross, and A. Ashworth. 1999. Absence of Brca2 causes genome instability by chromosome breakage and loss associated with centrosome amplification. Curr. Biol. 9: 1107-1110.

Vermes, I., C. Haanen, H. Steffens-Nakken, and C. Reutelingsperger. 1995. A novel assay for apoptosis. Flow cytometric detection of phosphatidylserine expression on early apoptotic cells using fluorescein labelled Annexin V.J. Immunol. Methods 184: 39-51.

Vogelstein, B. and K. Kinzler. 1993. The multistep nature of cancer. Trends Genet. 9: 138-141.

Wong, A.K.C., R. Pero, P.A. Ormonde, S.V. Tavtigian, and P.L. Bartel. 1997. Rad51 interacts with the evolutionarily conserved BRC motifs in the human breast cancer susceptibility gene BRCA2. J. Biol. Chem. 272: 31941-31944.

Yuan, S.S., S.Y. Lee, G. Chen, M. Song, G.E. Tomlinson, and E.Y. Lee. 1999. BRCA2 is required for ionizing radiationinduced assembly of Rad51 complex in vivo. Cancer Res. 59: 3547-3551.

Zhong, Q., C.F. Chen, S. Li, Y. Chen, C.C. Wang, J. Xiao, P.L. Chen, Z.D. Sharp, and W.H. Lee. 1999. Association of BRCA1 with the hRad50-hMre11-p95 complex and the DNA damage response. Science 285: 747-750. 


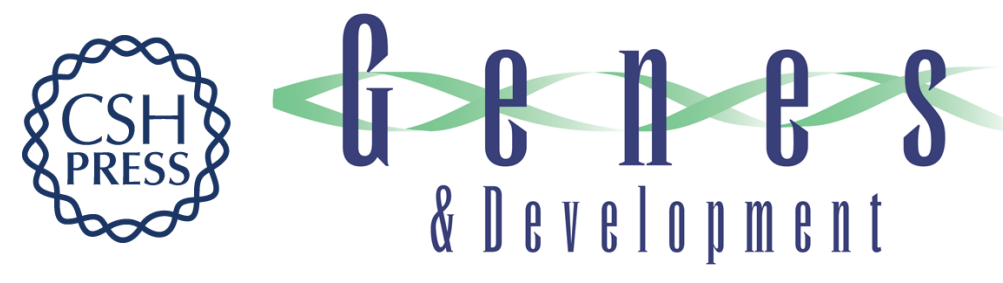

\section{Gross chromosomal rearrangements and genetic exchange between nonhomologous chromosomes following BRCA2 inactivation}

Veronica P.C.C. Yu, Michael Koehler, Claus Steinlein, et al.

Genes Dev. 2000, 14:

Access the most recent version at doi:10.1101/gad.14.11.1400

References This article cites 38 articles, 17 of which can be accessed free at: http://genesdev.cshlp.org/content/14/11/1400.full.html\#ref-list-1

License

Email Alerting

Receive free email alerts when new articles cite this article - sign up in the box at the top Service right corner of the article or click here.

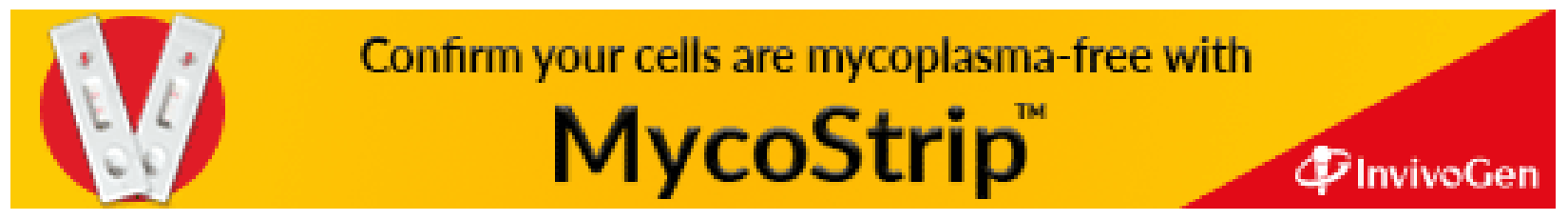

